\title{
A RECUPERAÇÃo INDIRETA DE ATIVOS NA PERSPECTIVA DE INVESTIGAÇốES NÃO COMPLEXAS
}

\author{
Breno Eduardo Campos Alves \\ Polícia Civil do Estado do Tocantins - TO
}

Romeu fernandes de Carvalho filho

Polícia Civil do Estado do Tocantins - TO

RESUMO

O presente artigo versa sobre a análise do direcionamento da gestão de segurança pública determinada pela matriz de política criminal de recuperação de ativos advindos de crimes, a qual visa tornar o crime não proveitoso. Desse modo, iremos amparar a raiz epistemológica da referida matriz, seu embasamento teórico e, a partir de então, realizaremos uma averiguação de uma perspectiva de sua aplicação em investigações criminais não complexas, verificando a possibilidade de autoridades policiais diminuírem os ganhos de criminosos, mesmo quando não descortinada a autoria delitiva.

Palavras-chave: investigação; crimes; recuperação; ativos; gestão.

\section{INTRODUÇÃo}

Tem sido recorrente nos cursos de atualizações policiais a implementação de ferramentas, estudos e aplicações de recuperação de ativos com objetivo de polícia criminal a ser perseguido pelas forças de investigação, visando destituir o caráter permanente da atuação da delinquência organizada impactando em seus ganhos (lucros) com a atividade criminosa.

Na construção legislativa temos a ENCCLA - Estratégia Nacional de Combate à Corrupção e à Lavagem de Dinheiro, "principal rede de articulação para o arranjo e discussões em conjunto com uma diversidade de órgãos (...) para a formulação de politicas públicas e soluçôes voltadas ao combate àqueles crimes" (ENCCLA, 2021), e, a partir desta, o PNLD 
- Programa Nacional de Capacitação e Treinamento para o Combate à Corrupção e à Lavagem de Dinheiro, o qual realiza a capacitação dos agentes públicos para a prevenção e o combate à corrupção.

Nesta matriz de política criminal que dia-a-dia vem ganhando espaço nas Polícias Civis e Federal, o combate ao branqueamento de capitais advindos de crimes anteriores como corrupção, tráfico ilícito de drogas, entre outros, levam a pontuais investigações policiais que visam minar, do ponto de vista econômico-financeiro, grupos criminosos estabelecidos e seus associados.

Diante desse cenário, o presente trabalho se presta a verificar uma nova perspectiva atinente à adequabilidade desta matriz de política criminal na atuação em investigações simples, isto é, levantando a seguinte questão: é possível que os operadores de segurança da área da investigação criminal atuem em investigações não complexas ${ }^{l}$ de acordo com a política de recuperar ativos - impedir que o delito resulte proveitoso?

Em primeiro momento, iremos realizar digressões conceituais que embasam a referida matriz de política criminal de segurança pública, valendo-se de contributos do Direito Penal, da Criminologia, da Economia e da própria ciência da Política Criminal. Em segundo momento, iremos abordar uma espécie criminal (roubo) e possíveis ações investigativas que de forma indireta possam resultar na diminuição do proveito do crime. Por fim, iremos sopesar os elementos expostos para chegarmos ao universo da microgestão de uma unidade de investigação e sua contribuição para a referida matriz de política criminal.

A presente investigação foi desenvolvida tomando-se por base a realidade criminal da cidade de Araguaína, situada ao norte do Estado do Tocantins. Cuida-se da segunda maior cidade do Estado, com área geográfica de 4.000 quilômetros quadrados e população estimada de 183.381 habitantes, conforme levantamento mais recente realizado pelo Instituto Brasileiro de Geografia e Estatística (IBGE, 2021).

1Expressão utilizada como antítese da expressão “investigações complexas” (quando há emprego de recursos operacionais especiais). “(...) a expressão 'meios extraordinários de investigação' engloba tanto as denominas técnicas especiais de investigação assim previstas na legislação (ação controlada, infiltração, interceptação de comunicações, colaboração premiada, v.g.), incluindo as que exigem autorização judicial para utilização ou validação, como as técnicas corriqueiramente utilizadas em investigações tradicionais, mas empregadas e executadas por efetivo especializado ou com recursos especiais". (SILVA, 2017, p. 24) 
Dentro desse universo criminal, o escopo da pesquisa se restringiu à análise dos possíveis impactos financeiros (custos) e, por conseguinte, reflexos preventivos de medidas que visem a recuperação indireta de ativos gerados a partir de delitos de roubos de aparelhos celulares. Tal recorte tem por objetivo ampliar a perspectiva de políticas criminais desse jaez, até então voltadas para grandes atividades financeiras ilegais, e, assim, abarcar investigações mais simples de infrações cotidianas.

Nessa senda, procederemos a uma breve digressão sobre os aspectos jurídicos do delito de roubo e, em seguida, explicitaremos os postulados gerais da abordagem econômica do crime, paradigma teórico-metodológico empregado no estudo.

\section{O CRIME DE ROUBO}

O crime de roubo encontra-se tipificado no artigo 157 do Código Penal, sendo definido em sua modalidade mais simples nos seguintes termos: "Subtrair coisa móvel alheia, para si ou para outrem, mediante grave ameaça ou violência a pessoa, ou depois de havê-la, por qualquer meio, reduzido à impossibilidade de resistência".

Da mera leitura do texto legal, conclui-se que a norma incriminadora tutela, em primeiro lugar, o patrimônio da vítima, mas também protege sua integridade física ou liberdade individual, a depender do meio de execução empregado (violência ou grave ameaça). Por esse motivo, a doutrina classifica o delito de roubo como crime complexo ou pluriofensivo, uma vez que resulta da fusão de dois delitos (furto e lesão corporal ou furto e ameaça), resguardando bens jurídicos distintos (MASSON, 2011, p. 353-354).

Como consectário lógico, o objeto material do crime de roubo é a coisa alheia móvel sobre a qual recai a conduta delituosa, mas também a pessoa contra quem se dirige a violência ou a grave ameaça.

O elemento subjetivo, por sua vez, é o dolo, exigindo o tipo penal ainda um especial fim de agir, traduzido na expressão "para si ou para outrem", isto é, o agente subtrai o bem de outrem com o ânimo de assenhoreamento definitivo (animus rem sibi habendi), comportando-se como se seu proprietário fosse. 


\subsection{A Teoria Econômica do Crime}

A abordagem econômica do crime toma como pressuposto que o infrator é um indivíduo que faz escolhas racionais, orientando-se a partir de critérios utilitários de custo/lucro (economic choice), o que "pressupõe que o crime é uma atividade ou 'indústria' economicamente relevante" (CARDOSO, 2018, p.185). Em outras palavras, o criminoso avalia as melhores oportunidades e age de forma pragmática, semelhante ao que ocorre na tomada de decisão de um consumidor frente à oferta de bens no mercado.

O modelo da escolha racional, à toda evidência, não reproduz rigorosamente o que acontece na realidade. Com efeito, os crimes não são produtos únicos e exclusivos da razão, mas também da emoção, da impulsividade, da ignorância ou, simplesmente, da pura irracionalidade. Porém, ainda que a teoria econômica não consiga explicar exatamente o processo subjetivo de tomada de decisão, ela permanece eficaz no que tange à descrição de comportamentos. A Economia, em última análise, é uma ciência comportamental.

\section{Conforme ensinam Robert Cooter e Thomas Ulen:}

(...) os consumidores agem como se estivessem calculando a utilidade marginal. Da mesma maneira, diz-se que os criminosos agem como se estivessem comparando os benefícios marginais do crime e as penas esperadas. (...) os criminosos podem não raciocinar tal e qual o modelo prevê, mas ainda agem como se tivessem. Ao dizer que os criminosos agem "como se" tivessem deliberado, dizemos que quando têm a oportunidade de cometer um crime, os criminosos respondem imediatamente aos riscos e benefícios com se os tivessem considerado.(COOTER; ULEN; 2010, p. 481)

Logo, mesmo que as escolhas humanas sejam de natureza complexa e, não raras vezes, não possam ser compreendidas racionalmente, as pessoas permanecem previsíveis. O comportamento humano é influenciado por incentivos favoráveis e desfavoráveis, sejam eles de ordem moral, biológica, psicológica, sociológica ou econômica, o que permite ao observador atento predizer, com elevada probabilidade de êxito, a opção que será adotada. 
Nessa esteira, o objetivo das políticas de segurança pública seria desestimular a prática de delitos a partir da maximização dos custos em detrimento dos potenciais ganhos resultantes da ação criminosa.

$\mathrm{Na}$ linguagem criminológica, a teoria econômica preconiza uma política prevencionista situacional, ou seja, focada em neutralizar as oportunidades que favorecem a prática de infrações penais. Nessa linha, ganham vulto as dimensões espaciais, temporais e situacionais do delito, uma vez que o crime não se trata de evento fortuito ou aleatório, mas racional, em que o autor analisa as melhores condições para agir.

Segundo Molina (2013, p.148), as técnicas de prevenção situacional podem ser classificadas em quatro grandes grupos, a saber:

a) As orientadas a incrementar a percepção do esforço associado a um particular delito;

b) As que incrementam a percepção do risco;

c) As tendentes a reduzir as recompensas esperadas;

d) As que perseguem potencializar os sentimentos de culpa do infrator.

À guisa de exemplo de medida orientada a incrementar a percepção do esforço, podemos citar a situação em que um particular decide instalar câmeras de vigilância e cercas elétricas em sua residência, cujo efeito esperado, sob a perspectiva do criminoso, será o desencorajamento devido à maior dificuldade na execução de um possível furto à residência, ainda que isso não impeça o redirecionamento do infrator para outra casa desguarnecida, efeito que os economistas denominam de redistribuição do crime.

Por sua vez, se o poder público decide aumentar significativamente a presença policial ostensiva nas ruas, bem como aparelhar as polícias investigativas visando aperfeiçoar sua eficiência, a consequência esperada, naturalmente, será o incremento da percepção do risco para o delinquente, tendo em vista a maior probabilidade de que venha a ser capturado e punido.

Técnicas de recuperação de ativos provenientes de corrupção ou de lavagem de dinheiro, com o objetivo de desarticular financeira- 
mente organizações criminosas e ressarcir o erário público, ilustram claramente providências voltadas à redução das recompensas auferidas com o crime.

Finalmente, como exemplo de medida do quarto grupo, podemos mencionar as pesadas indenizaçóes impostas a empresários como forma de internalização dos custos ambientais causados por atividades potencialmente poluidoras.

A eficácia de tais intervenções, por sua vez, são testadas a partir de estudos empíricos e equações matemáticas envolvendo diversas variáveis, sendo a notação mais conhecida desenvolvida pelo economista Gary S. Becker, em 1968, publicada por meio de seu artigo Crime and Punishment: in Economic Approach(1974).

Em sua tese, Becker sintetiza a noção de oferta do crime nos seguintes termos:

$$
\mathrm{O}=\mathrm{O}(\mathrm{p}, \mathrm{f}, \mathrm{u})
$$

em que " $O$ " significa número de crimes (offenses), " $p$ " indica a probabilidade (probability) de o indivíduo ser punido, " $f$ " é a pena (fine) aplicada à infração e " $u$ " designa outras variáveis a serem levadas em consideração, tais como nível de educação, oferta de trabalho etc.

Nessa ótica, a utilidade esperada da ofensa poderia ser traduzida na seguinte função matemática:

$$
\mathrm{E}(\mathrm{U})=\mathrm{pU}\left(\mathrm{Y}_{\mathrm{i}}-\mathrm{f}\right)+(1-\mathrm{p}) \mathrm{U}\left(\mathrm{Y}_{\mathrm{i}}\right)
$$

em que " $E(U)$ " é a utilidade esperada, " $p U$ " é a probabilidade de ser condenado, " $Y_{i}$ " é o retorno ilegal do crime e " $f$ " é a pena cominada ao delito.

Assim, suponhamos que um jovem oriundo dos estratos sociais menos abastados de uma comunidade e com baixa instrução ganhe, em média, $\mathrm{R} \$ 1.100,00$ (um mil e cem reais) mensais em um emprego formal. Imaginemos que esse mesmo jovem, caso decida roubar celulares, no mesmo período de um mês, aufira, em média, $\mathrm{R} \$ 7.500,00$ (sete mil e quinhentos reais). Vamos considerar que a probabilidade de um 
autor de roubo ser preso e condenado seja de $2 \%$ (dois por cento) ${ }^{2}$. Por fim, para simplificar nossa análise, suponhamos que a pena atribuída ao crime de roubo seja exclusivamente monetária e corresponda ao dobro do proveito delituoso.

Nesse caso, temos que a utilidade real do trabalho do jovem é $\mathrm{R} \$ 1.100,00$, uma vez que o desempenho da atividade legal não acarreta qualquer risco para o indivíduo. Assim:

$$
\mathrm{U}=\mathrm{U}\left(\mathrm{Y}_{1}\right)
$$

em que " $U$ " é a utilidade do emprego formal e " $Y_{l}$ " é a renda legal obtida com a atividade. Confira-se:

$$
\begin{gathered}
U=U(1100) \\
U=R \$ 1.100,00
\end{gathered}
$$

Por outro lado, a utilidade da atividade criminosa pode ser definida da seguinte forma:

$$
\begin{gathered}
\mathrm{E}(\mathrm{U})=\mathrm{pU}\left(\mathrm{Y}_{\mathrm{i}}-\mathrm{f}\right)+(1-\mathrm{p}) \mathrm{U}\left(\mathrm{Y}_{\mathrm{i}}\right) \\
\mathrm{E}(\mathrm{U})=0,02(7.500-15.000)+(1-0,02)(7.500) \\
\mathrm{E}(\mathrm{U})=0,02(-7.500)+0,98(7.500) \\
E(U)=-150+7.350 \\
E(U)=R \$ 7.200,00
\end{gathered}
$$

Diante desse cenário, podemos concluir que o indivíduo optaria pela empreitada criminosa, uma vez que o retorno líquido esperado supera em muito o benefício obtido com a atividade lícita.

2 De acordo com um levantamento realizado em 2018 pelo jornal Extra, com base em dados obtidos junto à Polícia Civil do Rio de Janeiro, de 60 roubos registrados, apenas 1 resulta em condenação para o criminoso, o que equivale a um percentual de $1,6 \%$. Infelizmente, esse percentual ainda é otimista, uma vez que não leva em consideração os casos de subnotificação (cifra negra) (BRAGA, 2018). 


\section{Uma Perspectiva De Microgestão: Estudo De Caso}

Considerando a base argumentativa acima evidenciada, temos, agora, a possibilidade de se analisar pontos valendo-nos de um estudo de caso.

Na cidade de Araguaína -TO, recorte da pesquisa, os registros de ocorrências policiais de crimes são feitos através de "uma plataforma de informações integradas, que possibilita consultas operacionais, investigativas e estratégicas sobre segurança pública, implementado em parceria com entes federados"(MINISTÉRIO DA JUSTIÇA, 2021), denominada SINESP.

Essas ocorrências, além do registro formal junto à plataforma acima explicitada, são cadastradas também junto à unidade da Polícia Civil de Araguaína, mediante um planilhamento de dados gerenciáveis, executado por uma aplicação de business intelligence (BI), que permite criar análises guiadas orientadas ao usuário, auxiliando na tomada de decisões, valendo-se de fontes diversas de conhecimento.

Desta forma, ao invés de utilizarmos uma classificação jurídica (típica) de ocorrências policiais, há uma catalogação policial investigativa, em outras palavras, é possível separar ocorrências pela natureza policial e não pela natureza jurídica típica. Ao contrário do ato de separar os crimes por roubos majorados com emprego de arma de fogo ou roubo majorado pela autoria de duas ou mais pessoas (ambos filtros jurídicos), é possível realizar filtros de roubos a estabelecimentos comerciais, roubos a transeuntes, roubos a veículos etc. (filtros policiais). Vejamos: 
Figura 1 - Extração da análise gerenciável de ocorrências policiais de roubo

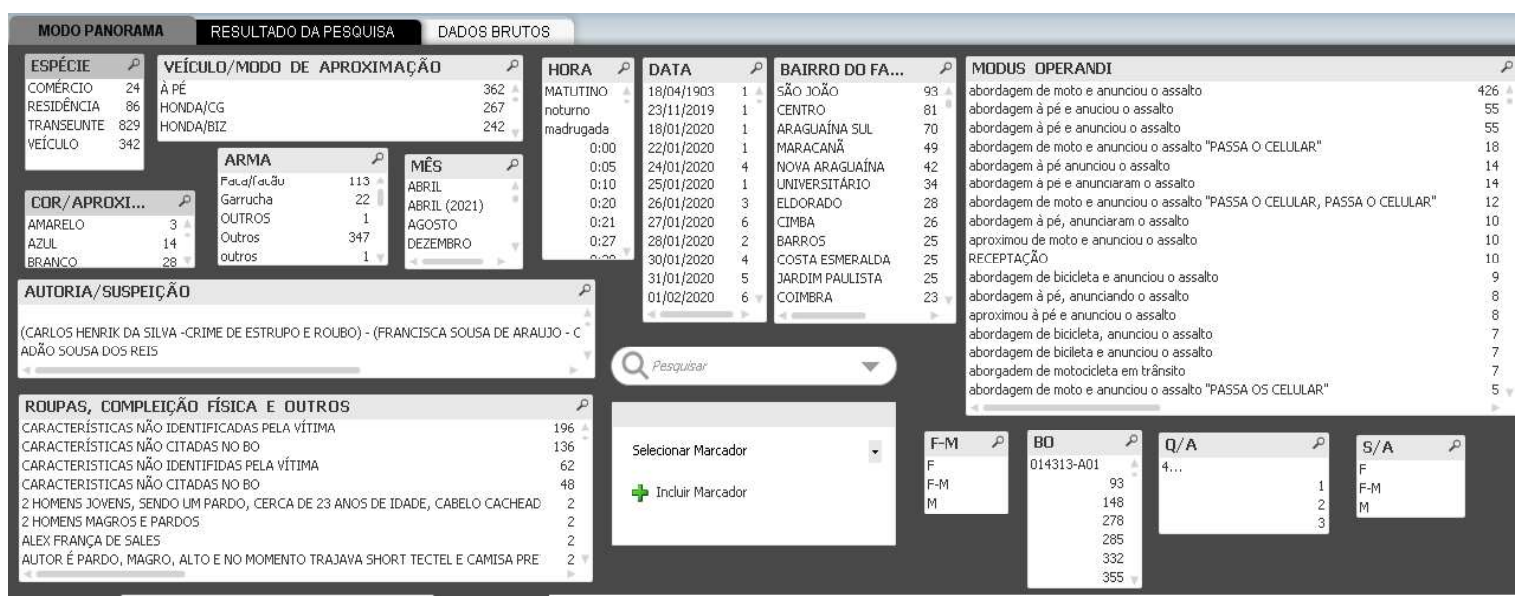

Fonte: Autores

Dessa forma, valendo-se desta metodologia, é possível realizarmos o filtro e recorte para crimes de roubo a transeuntes, os quais, em quase sua totalidade, refletem na subtração por violência e grave ameaça dos pertences que a vítima leva consigo, entre eles, o seu aparelho celular. Aplicando o filtro desta modalidade criminal, temos, no ano de 2020, o mês de novembro como o de maior índice matemático de crimes de roubo a transeunte, obtendo a quantidade de 75 ocorrências policiais, vejamos:

Figura 2 - Extração da análise gerenciável de ocorrências policiais de roubo a transeuntes no mês de novembro de 2020 na cidade de Araguaína-TO

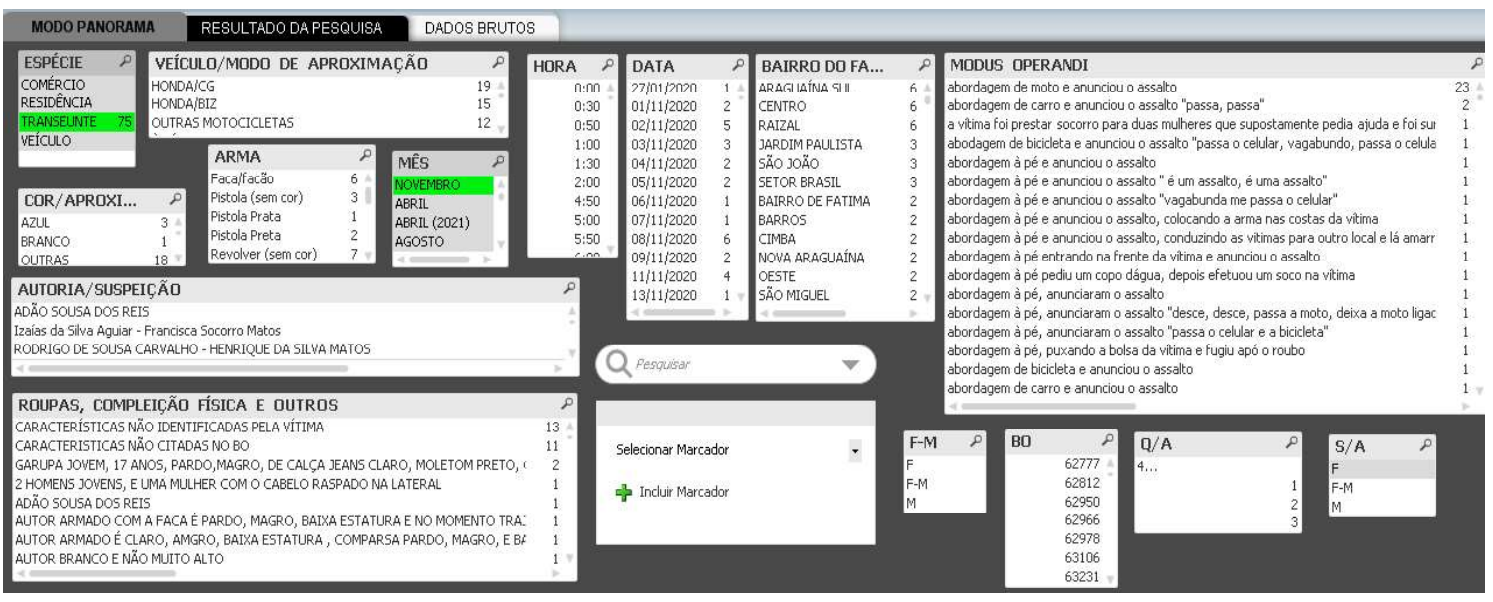

Fonte: Autores 
Desse modo, planilhamos as ocorrências policiais de modo a identificar os modelos dos aparelhos celulares subtraídos nos crimes ocorridos no mês de novembro, e, valendo-se de um cálculo de projeção, após pesquisa mercadológica dos aparelhos subtraídos em dez eventos criminais, chegamos ao valor de $\mathrm{R} \$ 11.291,55^{3}$ (onze mil duzentos e noventa e um reais e cinquenta e cinco centavos) para dez eventos. Em resumo, desconsiderando prejuízos adicionais atinentes a outros bens subtraídos e considerando apenas os aparelhos celulares roubados, temos que cada crime/evento importou em um impacto médio de $\mathrm{R} \$ 1.129,15$ (mil cento e vinte e nove reais e quinze centavos).

\section{Tabela 1 - PLANILHA DE PRECIFICAÇÃO}

\begin{tabular}{|c|c|c|}
\hline B.O. & MARCA MODELO & PRECIFICAÇÃO \\
\hline 64539 & Samsung, modelo A50 & $1.429,00$ \\
\hline 64322 & Samsung, modelo J2 & 699,00 \\
\hline 64295 & Samsung, modelo J5 Prime & $1.299,00$ \\
\hline 63551 & Samsung, modelo A10S & 799,00 \\
\hline 62621 & Samsung, modelo J5 Prime & $1.299,00$ \\
\hline & Samsung, modelo J5 & 780,00 \\
\hline 68179 & Samsung, modelo J2 PRIME 16GB & 799,00 \\
\hline 66902 & Apple, modelo Iphone 5S & $1.199,00$ \\
\hline 66007 & Samsung, modelo J2 & 699,00 \\
\hline 65522 & Samsung, modelo J4 & 799,00 \\
\hline & SOMATÓRIA DOS VALORES & $11.291,55$ \\
\hline & DIVISÃO POR EVENTO & $1.129,15$ \\
\hline
\end{tabular}

Fonte: Autores

Ainda, no recorte temporal que referendamos, um mês, projetando para os setenta e cinco crimes/eventos, temos que estes impactaram em um referencial médio/mês de $\mathrm{R} \$ 84.686,25$ (oitenta $\mathrm{e}$ quatro mil seiscentos e oitenta e seis reais e vinte e cinco centavos). Por fim, ampliando para uma perspectiva anual, teríamos o valor médio de $\mathrm{R} \$ 1.016 .235,00$ (um milhão dezesseis mil duzentos e trinta e cinco reais) em prejuízos impactados, suportados pelas vítimas.

3 Pesquisa realizada mediante consulta em sítios de venda pela internet, a qual considerou o valor do aparelho novo, todavia, em relação à depreciação do produto usado, temos uma compensação em virtude da desconsideração de eventuais outros bens subtraídos no crime. 
Avançando, consideremos que o autor do crime de roubo tenha em mãos um aparelho no valor de $\mathrm{R} \$ 1.129,15$, após ter conseguido realizar o crime, assim, temos que o prejuízo $(\mathrm{R} \$ 1.129,15)$ já foi suportado pela vítima, pois já se trata de um valor (ativo) perdido por ela. Desta forma, quando em um ato post delictum o agente do roubo, por exemplo, efetua a venda pela metade do valor de mercado, ele obtém um ganho, no nosso exemplo, de $\mathrm{R} \$ 561,57$ (metade do valor), mas, nominalmente, é um valor (ativo) de incremento ao prejuízo já recaído à vítima durante o crime, pois somando o prejuízo da vítima, mais o ganho do autor, chegamos a um valor de $\mathrm{R} \$ 1.693,72$. Assim, o aparelho (ativo) vai ingressar novamente na circulação de bens comuns da vida cotidiana, tendo o receptador (de boa-fé ou de má-fé) a possibilidade de revendê-lo a um terceiro, que também poderá comercializá-lo, sempre acrescendo valores até que alcance novamente o seu valor real de mercado.

Em outras palavras, o que explicitamos é que o crime não impacta economicamente apenas a vítima, esta suportou o prejuízo inicial do valor do bem subtraído e este não será ressarcido, então, quando o criminoso efetua a venda do bem a terceiro, temos um novo valor agregado aos impactos do crime, pois alguém irá pagar, agora, um valor pelo bem, o qual será, em sua totalidade, lucro da atividade criminosa. Assim, o valor de impacto do crime é a soma do prejuízo da vítima com o lucro advindo da destinação posterior do aparelho, passando ambos a ser um ativo criminal.

O que temos em análise real, além do valor "x" suportado pela vítima, são negociações posteriores entre autor do roubo e receptadores que vão tender a chegar novamente ao real valor do aparelho, na medida em que essas vendas forem ocorrendo no mercado informal. Na práxis policial percebemos que um aparelho celular, após ser roubado, acaba sendo vendido a um receptador por preços que variam entre 30 a 50\% do preço de mercado; após, o receptador, diante do aparelho com baixo custo, efetua a venda com valores entre 50 a $70 \%$ a um segundo receptador; por fim, temos um terceiro receptador, para o qual o aparelho já chega entre 70 a $100 \%$ do valor do mercado. Sob essa ótica, podemos notar que se as negociações escusas dos aparelhos roubados tendem a devolver ao respectivo objeto o seu preço de mercado, pois quanto mais perto do valor real, geralmente, maior a proximidade e confiança entre o comprador e vendedor, assim, considerando o 
objetivo exposto neste artigo, chegamos à hipótese de que o impacto econômico que o crime de roubo de um aparelho celular causa é proporcional a duas vezes o seu valor e, embora seja apenas uma hipótese, iremos trabalhá-la para exemplificar a aplicação prática.

Para clarear ainda mais, repisamos o último receptador que pagou, hipoteticamente, a quantia de $100 \%$ do valor de mercado em um aparelho que detém origem criminosa, logo, valendo-se do nosso recorte de estudo em exemplo, ele pagou a quantia de $\mathrm{R} \$ 1.129,15$. Este valor foi repartido, em lucro, por todos da cadeia de compra e venda, desde o ingresso do aparelho no mercado informal, e se tratou de um ativo que foi proveniente do crime, então, se considerarmos um grupo matemático chamado "efeitos financeiros do crime" e alocarmos nele o valor que a vítima perdeu quando teve seu objeto subtraído, aliado ao valor pelo qual o receptador comprou o bem - aqui em representação a todos os receptadores, até alcançar aquele que pagará o valor real de mercado do bem -, teremos, em somatória dos itens do grupo, o dobro do valor do objeto roubado.

\subsection{DA PROPOSTA DE INTERVENÇÃO EM INVESTIGAÇÕES NÃO COMPLEXAS: BLOQUEIO DE USO DE APARELHOS CELU- LARES ROUBADOS}

Em primeiro quadro, conforme já mencionado no decorrer deste trabalho, temos que o crime de roubo tem taxa de resolução/ condenação baixa, variando entre 1 e $5 \%$ o percentual de roubos em que há efetiva apuração, conforme declarações de secretários estaduais de segurança pública ${ }^{4}$. Então, aplicando tais índices à nossa proposta, temos que, em cada 100 roubos de aparelhos celulares, 95 não serão apurados. Na práxis policial, essas 95 ocorrências serão sobrestadas/ arquivadas, não gerando nenhum procedimento, o que a doutrina de ciências policiais vem apregoando como "seletividade".

Em segundo quadro, temos o Projeto Celular Legal da Agência Nacional de Telecomunicações - ANATEL, sendo que, em consonância com a Lei Geral de Telecomunicações, Lei 9.472, de 16 de julho de 1997, todos os aparelhos que utilizam SIM Card de operadora de telefonia móvel devem possuir certificação aceita pela ANATEL.

4 Pouca pesquisa de dados nesta área, sendo recorrente as pesquisas em torno de homicídios. 
Desta forma, o Delegado de Polícia, quando diante de casos de roubos de aparelhos celulares, tendo em vista a quantidade de crimes em que não irá atuar procedendo investigações complementares - o que se denota do índice acima referendado -, pode encaminhar, via ofício de sua lavra, a numeração de identificação do aparelho (IMEI) para a operadora de telefonia móvel, solicitando a inclusão na popular blacklist ${ }^{5}$, ou seja, o aparelho passará a não poder ser utilizado junto à malha de telefonia móvel.

Dois pontos merecem destaque quanto a esta medida: (i) é aplicável em investigações nas quais não houve o start investigativo de seguimento, ou seja, boletins de ocorrências sobrestados/arquivados; ademais, considerando o caráter rastreável de um aparelho de telefonia, as investigações policiais podem ser assessoradas com informações advindas do uso posterior do referido aparelho, motivo pelo qual a sua não inabilitação pode ser uma estratégia investigativa; (ii) o congestionamento de ocorrências policias, conforme acima explanado, de modo que o volume de boletins de ocorrências que não são investigados é alto, resultando em fatos que, possivelmente, não se chegue à autoria delitiva.

Passaremos agora a idealizar os possíveis impactos econômicos da medida de inclusão do aparelho celular junto à lista de bloqueio da ANATEL.

Consideremos que o crime já ocorreu, logo, o prejuízo da vítima ( $\mathrm{R} \$ 1.129,15)$, conforme supracitado, já foi suportado; todavia, o agente, ao efetuar a venda, não conseguirá alcançar os supostos $50 \%$ do valor de mercado, vez que o aparelho perderá a usabilidade funcional. Neste ponto, quanto mais perto o ato de bloqueio do crime em si, maior a capacidade de diminuir os impactos financeiros do crime, pois a única serventia do aparelho passaria a ser a negociação como sucata para peças.

Noutro giro, se o aparelho é efetivamente vendido e percorre a cadeia de receptadores, a qual já explanamos, mesmo que já esteja com um quinto receptador, por exemplo, na cadeia sucessória, ao ser desativado, perderá parte do seu valor, não podendo ser disposto pelo valor normal de mercado e, novamente, somente usado como sucata/peças.

5 Lista negra. 
Conforme exposto nas digressões iniciais, considerando os quadros acima alinhavados, temos, nesta semiconclusão, uma medida tendente a reduzir as recompensas esperadas pelo crime, sendo uma técnica de prevenção situacional, (MOLINA, 2013, P. 148).

Nesta proposição, temos, como hipótese do nosso estudo de caso, que em cada mês os crimes de roubo a transeuntes com subtração de aparelho de telefonia móvel geram um impacto econômico, em média, de $\mathrm{R} \$ 84.686,25$ em prejuízos às vítimas, o qual, em análise do pós-crime, na qual o valor é dobrado, alcança a quantia de $\mathrm{R} \$ 169.372,50$, montante este que adentra no mercado em decorrência do crime. Assim, considerando a média no período de um ano, temos o valor de $\mathrm{R} \$ 2.032 .440,00$ (dois milhões trinta e dois mil quatrocentos e quarenta reais).

Por fim, se o implemento da medida de bloqueio se efetivar, o valor de $\mathrm{R} \$ 2.032,440,00$ tende a se reduzir pela metade, sendo que ainda que efetivamente seja alcançado algum valor com a venda do aparelho, este perderá o seu valor integral em algum momento e, novamente, tenderá a sua não comercialização. Assim, em um cenário hipotético, chegamos à possibilidade de redução de até 50\% (cinquenta por cento) dos ativos provenientes da prática do crime de roubo e dos crimes posteriores de receptações, diminuindo, assim, cerca de um milhão de reais da atividade ilícita, reduzindo as recompensas do autor (técnica de prevenção situacional).

\section{Conclusão}

O presente artigo expôs os fundamentos da matriz de atuação em segurança pública que embasam as políticas de recuperação de ativos, normalmente relacionadas a grandes operações policiais e ao desnude de organizações criminosas. Assim, explorou-se a contextualização criminológica, a teoria econômica do crime e o assentamento da prevenção situacional como medida de atuação estatal.

Em sequência, trabalhamos uma hipótese de aplicação da referida matriz na perspectiva de atuação de investigações não complexas, verificando a eficácia desta atuação na mesma linha trabalhada em investigações de maior complexidade. 
Através de um estudo de caso sobre roubos de aparelhos celulares na cidade de Araguaína/TO, concluímos que é possível realizar medidas que estão em consonância com a matriz de recuperação de ativos e de redução do proveito econômico do crime, mesmo em investigações não complexas, sendo que, no presente caso, verificamos, hipoteticamente, os efeitos da medida de bloqueio de aparelhos roubados.

Nesse sentido, o presente estudo demonstra que o emprego de medidas investigativas tomadas em investigações não complexas também podem ser úteis para contribuir com os objetivos dos programas nacionais direcionados a tornar as condutas criminosas menos lucrativas, com o que se espera ampliar o debate sobre as possibilidades de aplicação das técnicas de recuperação de ativos.

\section{Breno Eduardo Campos Alves}

Delegado de Polícia Civil - Delegacia de Repressão a Roubos de Araguaína/TO

Ex-Investigador de Polícia do DENARC/MG ESPECIALISTA EM INVESTIGAÇÃo DO NARCOTRÁFICO Ministério do INTERIOR DA RÚSSIA Pós-Graduado em Gestão em Segurança Pública FAMART

Pós-Graduado em Direito em Administração Pública EXERCITO BRASILEIRO

Pós-Graduado em Cî̂ncias Criminais - MILTON

CAMPOS

http://lattes.cnpq.br/0270114850933320

Romeu Fernandes de Carvalho Filho

Delegado de Polícia da 29a Delegacia de Polícia Civil de Araguaína/TO.

Ex-Cadete da Polícia Militar do Estado do Goiás. Especialista em Criminologia e Segurança Pública -UFG

http://lattes.cnpq.br/5204822772575666 


\title{
THE INDIRECT ASSET RECOVERY FROM THE PERSPECTIVE OF NON-COMPLEXINVESTIGATIONS
}

\begin{abstract}
This article deals with the analysis of the direction of public security management determined by the criminal policy matrix for the recovery of assets arising from crimes, which aims to make crime unprofitable, thus, we will support the epistemological root of that matrix, its foundation theoretical and, from then on, we will carry out an investigation from the perspective of its application in small criminal investigations, verifying the possibility of police authorities reducing the criminals' earnings, even when the criminal authorship is not revealed.
\end{abstract}

KEYWORDS: investigation; crimes; recovery; active; management.

\section{LA RECUPERACIÓN DE ACTIVOS INDIRECTOS DESDE LA PERSPECTIVA DE INVESTIGACIONES NO COMPLEJAS}

\section{RESUMEN}

Este artículo aborda El análisis de La dirección de La gestión de La seguridad pública determinada por la matriz de política penal para La recuperación de activos derivados de delitos, que tiene como objetivo hacer que el delito no sea rentable, por lo que apoyaremos la raíz epistemológica de esa matriz, su fundamento teórico. y, a partir de ahí, realizaremos una investigación desde la perspectiva de su aplicación em pequenas investigaciones penales, verificando la posibilidad de que las autoridades policiale sreduzcan las ganancias de los delincuentes, incluso cuando no se revele la autoria delictiva.

Palabras-Clave: investigación; crimenes; recuperación; activo; administración. 


\section{REFERENCIAS}

BECKER, Gary. Crime and Punishment: An Economic Approach. 1974. Disponível em: <https://www.nber.org/system/files/chapters/ c3625/c3625.pdf>. Acesso em: 01 jun. de 2021.

BRAGA, Giampaolo Morgado. Baixo número de crimes investigações é prêmio para os bandidos. Revista Época, out. de 2018. Disponível em: <https://epoca.globo.com/baixo-numero-de-crimesinvestigados-premio-para-os-bandidos-23162345>. Acesso em: 02 jun. de 2021

BRASIL. Decreto-Lei no 2.848, de 07 de dezembro de 1940. Presidência da República. Casa Civil. Disponível em: http://www. planalto.gov.br/ccivil_03/decreto-lei/del2848.htm. Acesso em: 03jun. 2021

BRASIL. Lei no 9.472, de 16 de julho de 1997. Presidência da República. Casa Civil. Disponível em: http://www.planalto.gov.br/ ccivil_03/leis/19472.htm. Acesso em: 01jun. 2021

CARDOSO, L. E. D. O conceito normativo de crime na teoria econômica de Gary Becker. Dissertação (Mestrado em Direito) - Centro de Ciências Jurídicas, Universidade Federal de Santa Catarina, Florianópolis, 2018. Disponível em: https://repositorio. ufsc.br/bitstream/handle/123456789/186768/PDPC1391-D. pdf ?sequence $=-1$. Acesso em: 01jun. 2021.

COOTER, Robert; ULEN, Thomas. Direito \& Economia. - $5^{\mathrm{a}}$ ed. (trad.). Porto Alegre: Bookman, 2010.

ENCCLA - Estratégia Nacional de Combate à Corrupção e à Lavagem de Dinheiro. Quem somos. Disponível em: <http://enccla. camara.leg.br/quem-somos>. Acesso em: 03 jun. de 2021.

IBGE - INSTITUTO BRASILEIRO DE GEOGRAFIA E ESTATÍSTICA. Araguaina. Disponível em: <Disponível em: https://cidades.ibge.gov.br/brasil/to/araguaina/panorama $>$. Acesso em: 02 jun. de 2021.

MASSON, Cleber Rogério. Direito penal esquematizado: parte especial. - $3^{\mathrm{a}}$ ed. - Rio de Janeiro: Forense; São Paulo: Método, 2011, vol. 2. 
MINISTÉRIO DA JUSTIÇA. SINESP - Sistema Nacional de Informações de Segurança Pública. Disponível em: $<$ Disponível em: <https://www.novo.justica.gov.br/sua-seguranca-2/segurancapublica/sinesp-1/o-sinesp-1/o-sinesp>. Acesso em: 02 jun. de 2021.

MOLINA, Antonio García-Pablos de. O que écriminologia?; tradução Danilo Cymrot. - 1. ed. - São Paulo: Editora Revista dos Tribunais, 2013.

SILVA, Élzio Vicente da. Operações Especiais de Polícia Judiciária. Barueri, SP: Novo Século Editora, 2017. 